\title{
The association of education with body mass index and waist circumference in the EPIC-PANACEA study
}

Silke Hermann ${ }^{1}$, Sabine Rohrmann ${ }^{1,37^{*}}$, Jakob Linseisen ${ }^{1,2}$, Anne M May ${ }^{3,4}$, Anton Kunst ${ }^{5}$, Herve Besson ${ }^{3,6}$, Dora Romaguera ${ }^{7}$, Noemie Travier ${ }^{8}$, Maria-Jose Tormo ${ }^{9,10,11}$, Esther Molina ${ }^{11,12}$, Miren Dorronsoro ${ }^{11,13}$, Aurelio Barricarte ${ }^{11,14}$, Laudina Rodríguez ${ }^{15}$, Francesca L Crowe ${ }^{16}$, Kay-Tee Khaw ${ }^{17}$, Nicholas J Wareham ${ }^{6}$, Petra GA van Boeckel ${ }^{4}$, H Bas Bueno-de-Mesquita ${ }^{4}$, Kim Overvad ${ }^{18,19}$, Marianne Uhre Jakobsen ${ }^{19}$, Anne Tjønneland ${ }^{20}$, Jytte Halkjær ${ }^{20}$, Claudia Agnoli ${ }^{21}$, Amalia Mattiello ${ }^{22}$, Rosario Tumino ${ }^{23}$, Giovanna Masala ${ }^{24}$, Paolo Vineis ${ }^{25,26}$, Androniki Naska 27 , Philippos Orfanos ${ }^{27}$, Antonia Trichopoulou ${ }^{27,28}$, Rudolf Kaaks ${ }^{1}$, Manuela M Bergmann ${ }^{29}$, Annika Steffen ${ }^{29}$, Bethany Van Guelpen ${ }^{30}$, Ingegerd Johansson ${ }^{31}$, Signe Borgquist ${ }^{32}$, Jonas Manjer ${ }^{33}$, Tonje Braaten ${ }^{34}$, Guy Fagherazzi ${ }^{35}$, Françoise Clavel-Chapelon ${ }^{35}$, Traci Mouw ${ }^{7}$, Teresa Norat ${ }^{7}$, Elio Riboli ${ }^{7}$, Sabina Rinaldi ${ }^{36}$, Nadia Slimani ${ }^{36}$, Petra HM Peeters ${ }^{3}$

\begin{abstract}
Background: To examine the association of education with body mass index (BMI) and waist circumference (WC) in the European Prospective Investigation into Cancer and Nutrition (EPIC).

Method: This study included 141,230 male and 336,637 female EPIC-participants, who were recruited between 1992 and 2000. Education, which was assessed by questionnaire, was classified into four categories; BMI and WC, measured by trained personnel in most participating centers, were modeled as continuous dependent variables. Associations were estimated using multilevel mixed effects linear regression models.

Results: Compared with the lowest education level, BMI and WC were significantly lower for all three higher education categories, which was consistent for all countries. Women with university degree had a $2.1 \mathrm{~kg} / \mathrm{m}^{2}$ lower BMI compared with women with lowest education level. For men, a statistically significant, but less pronounced difference was observed $\left(1.3 \mathrm{~kg} / \mathrm{m}^{2}\right)$. The association between WC and education level was also of greater magnitude for women: compared with the lowest education level, average WC of women was lower by $5.2 \mathrm{~cm}$ for women in the highest category. For men the difference was $2.9 \mathrm{~cm}$.
\end{abstract}

Conclusion: In this European cohort, there is an inverse association between higher BMI as well as higher WC and lower education level. Public Health Programs that aim to reduce overweight and obesity should primarily focus on the lower educated population.

\footnotetext{
* Correspondence: sabine.rohrmann@ifspm.uzh.ch

'Division of Cancer Epidemiology, German Cancer Research Centre,

Heidelberg, Germany

Full list of author information is available at the end of the article
} 


\section{Background}

Overweight and obesity are growing problems worldwide with a prevalence of overweight and obesity of $60 \%$ for European women and $70 \%$ for men in the age group of 45-59 years [1]. Being overweight or obese increases the risk of some types of cancer, cardiovascular disease, hypertension, diabetes mellitus type 2, gallstones, osteoarthritis, or sleep apnea [2]. In most Western countries, there is a clear association between socioeconomic status (SES) and the risk of becoming overweight or obese as pointed out by McLaren [3]. Data from NHANES 1999/2000 survey have shown a higher prevalence of obesity in low educated men and women compared with high educated subjects, although the difference between these groups decreased between the survey in the early 1970s and the 1999/2000 survey [4]. In the WHO MONICA project, years of schooling and BMI were also significantly inversely associated [5]. In contrast to the US results, MONICA results indicate an increase in the gap between obesity in less and better educated subjects in most of the participating centers. It is interesting to note that in both surveys a trend towards a higher education in the survey populations has been observed.

Although body mass index (BMI) is the most commonly used anthropometric measure of obesity, other measures such as waist circumference (WC) are increasingly being used. WC is of special interest since previous evaluations of the European Prospective Investigation into Cancer and Nutrition (EPIC) have shown that WC was stronger related to overall mortality than BMI [6]. EPIC-PANACEA (Physical Activity, Nutrition, Alcohol, Cessation of smoking, Eating out of home And obesity) offers the opportunity to evaluate the association between highest educational level attained and measurements of BMI and $\mathrm{WC}$ in a large European population.

\section{Methods}

\section{Population and study design}

EPIC is an ongoing multi-centre prospective cohort study consisting of 23 centres in 10 countries (Denmark, France, Germany, Greece, Italy, the Netherlands, Norway, Spain, Sweden and the United Kingdom). From 1992 to 2000, more than 500,000 individuals (in majority 35 to 70 years of age) were recruited from the population living in a defined geographical region. Recruitment procedures have been described in detail by Riboli et al. [7]. The cohort of France is based on female members of a health insurance plan for school employees; parts of the Italian and Spanish cohorts included members of local blood donors associations; the cohorts from Utrecht (The Netherlands) and Florence (Italy) recruited participants of breast cancer screening programs; and the Oxford cohort consisted of vegetarians, vegans and other health-conscious individuals. In France, Norway, Utrecht (The Netherlands) and Naples (Italy) only women were recruited [7]. Baseline information on education, occupation, medical history, tobacco smoking, physical activity and reproductive history were assessed using questionnaires and/or interviews. Usual diet was measured by country-specific assessment instruments. Seven countries adopted an extensive self-administered dietary questionnaire. In Greece, Spain and Ragusa a dietary questionnaire was administered by direct interview. A food frequency questionnaire and a seven-day record were adopted in the UK. In Malmö, Sweden, a quantitative questionnaire combined with a 7-day menu book and an interview was used [7]. Approval for this study was obtained from the ethical review boards of all participating institutions.

Of the total cohort of 519,931 apparently healthy subjects, we excluded subjects with missing information on dietary and non-dietary variables $(\mathrm{n}=6,675), \mathrm{BMI}(\mathrm{n}=$ $4,011)$, or education $(n=20,170)$, subjects with an extreme ratio of energy intake to energy expenditure $(\mathrm{n}=10,209)$, pregnant women $(\mathrm{n}=623)$, and subjects with implausible anthropometric measurements $(\mathrm{n}=$ 376). The analytical cohort consisted of 141,230 men and 336,637 women.

\section{Anthropometric measurements}

In most EPIC centres height and weight were measured at recruitment following a standardized procedure and is described in detail elsewhere [8]. In France, Oxford and Norway, self-reported data were obtained from all individuals. For part of the Oxford (UK) cohort, for which measured data were not available, linear regression models were used to predict sex- and age-specific values from subjects with both measured and selfreported body measures $[9,10]$. In each centre, WC was measured either at the narrowest torso circumference or midway between the lower ribs and the iliac crest. To reduce heterogeneity due to protocol differences in clothing worn during measurement, correction factors of $-1.5 \mathrm{~kg}$ for weight and $-2.0 \mathrm{~cm}$ for $\mathrm{WC}$ were adopted for subjects who were normally dressed and without shoes, while an adjustment for weight of $1.0 \mathrm{~kg}$ was applied for subjects in light clothing [8]. While BMI information (measured or self-reported) was available for all subjects, WC measurements were only available for $73 \%$ of the subjects as waist circumference has not been measured in Norway, Umea (Sweden), and in the majority of the French cohort.

BMI was calculated as weight $(\mathrm{kg})$ divided by height (m) squared. We used the following BMI categories: < $18.5 \mathrm{~kg} / \mathrm{m}^{2}$, underweight; $\mathrm{BMI} \geq 18.5$ to $<25 \mathrm{~kg} / \mathrm{m}^{2}$, 
normal weight; $\mathrm{BMI} \geq 25$ to $<30 \mathrm{~kg} / \mathrm{m}^{2}$, overweight; BMI $\geq 30 \mathrm{~kg} / \mathrm{m}^{2}$, obese.

\section{Highest Level of Education}

Educational level, based on highest school level reached (university, secondary, technical or professional, primary, or none), was used as a proxy for SES. This variable was categorized into: (1) primary school or less; (2) vocational secondary education; (3) other secondary education; and (4) university degree.

\section{Covariates}

Recruitment age, smoking, physical activity, alcohol consumption, total energy intake and marital status were taken into account as co-variables. Smoking status was categorized as current, former, never and missing. To adjust for the level of physical activity, a five-level validated variable (inactive, moderately inactive, moderately active, active, and missing) was created [11]. Information on alcohol consumption reflected the amount of alcohol consumed daily during the 12 months prior to recruitment. This information was summarized in a six-level variable for women (non consumers, 1-6, 7-18, 19-30, $31-60,>60 \mathrm{~g} /$ day) and a seven-level variable for men (non consumers, 1-6, 7-18, 19-30, 31-60 g/day, 61-96, > $96 \mathrm{~g} /$ day). Total energy intake was computed from the dietary assessment instruments. Marital status was categorised as single/separated/widowed, living together/ married and missing.

\section{Statistical methods}

The associations between BMI, WC and education were examined for the total EPIC cohort and by country. All analyses were carried out by sex. The association between education and BMI or WC across all countries was estimated using multilevel mixed linear models with random intercepts and coefficients both at the centre and country level. The analysis by countries was done depending on the number of study centres per country. For countries with only one centre (i.e., the Netherlands [men], France, Norway, and Greece), adjusted linear models were run. For countries with more than one study centre (i.e., Italy, Spain, the Netherlands [women], Sweden, Denmark, Germany, and United Kingdom,), adjusted mixed linear models with random intercept at centre level were used to assess the association between highest education level and BMI/WC.

In all models, BMI and WC were modelled as continuous variables. Education level was the independent variable and modelled using a categorical variable. Age at recruitment and total energy intake were entered in the models as continuous variables while physical activity, smoking, and alcohol consumption were entered in the models as categorical variables. Further adjusting for marital status did not change our results and was not included in the final models. Secondary analyses were performed by age group (age at recruitment $</ \geq$ 60 years), smoking status, categories of alcohol consumption $(0-<6 / \geq 6 \mathrm{~g} /$ day $)$, as well as by BMI $(</ \geq 25 \mathrm{~kg} / \mathrm{m} 2)$ and WC $(</ \geq 88 \mathrm{~cm}$ in women; $</ \geq 102 \mathrm{~cm}$ in men [12]). All statistical analyses were performed with SAS software version 9.1 (SAS Institute, Cary, NC, USA).

\section{Results}

The distribution of educational levels varies widely in the EPIC cohort (Table 1). The percentage of men having only completed primary school ranged from $10.9 \%$ (Dutch cohorts) to $38.7 \%$ (Spanish centers); in women, the country with the lowest percentage of subjects that have only completed primary school was in the French cohort, which consists of female school employees (11.1\%) and highest in the Spanish cohorts (41.8\%). In the Italian cohorts, $14.4 \%$ of men had a university degree compared to $42.5 \%$ in the two German cohorts; in women, the lowest percentage of women with university degree was observed in the Spanish cohorts (10.0\%) and the highest in the British cohorts (39.5\%). Besides the Greek and the Spanish cohorts, only few study participants fell into the category with no formal educational degree. Therefore, we had combined the categories "no degree" and "primary school completed" into "primary school or less".

Baseline characteristics of the study participants are shown in Table 2. Subjects with a low educational level were oldest at time of recruitment, had the highest prevalence of overweight and obesity of all education categories, and reported the lowest level of physical activity. Men and women with a university degree were less often current smokers than participants who were less educated. Women with the lowest education also had the lowest alcohol consumption.

Compared to women with lowest education, women with a university degree had a $2.12 \mathrm{~kg} / \mathrm{m}^{2}$ lower BMI (Table 3). For men, result was similar although less pronounced $\left(1.28 \mathrm{~kg} / \mathrm{m}^{2}\right)$. Crude results were similar compared with fully adjusted models. The difference between lowest and highest education group was larger in younger than in older women. The difference in BMI was also stronger in younger men, but less pronounced than in women. In women, the difference between highest and lowest educational group was stronger in never than in current smokers, but the confidence intervals were wide and overlapping. We observed strongly attenuated associations of education with BMI in non-obese subjects. In women, but not in men, the difference between highest and lowest education status was still statistically significant in non-obese subjects, but the difference was merely 0.5 BMI units. 
Table 1 Distribution of EPIC participants by sex, country, and highest level of education attained

\begin{tabular}{|c|c|c|c|c|c|c|c|c|c|c|c|}
\hline & & \multicolumn{5}{|c|}{ Men } & \multicolumn{5}{|c|}{ Women } \\
\hline & & \multicolumn{5}{|c|}{ Educational Level } & \multicolumn{5}{|c|}{ Educational Level } \\
\hline & & 1 & 2 & 3 & 4 & Total & 1 & 2 & 3 & 4 & Total \\
\hline \multirow[t]{2}{*}{ France } & $n$ & - & - & - & - & - & 7944 & - & 35437 & 25699 & 69080 \\
\hline & $\%$ & - & - & - & - & - & 11.5 & - & 51.3 & 37.2 & \\
\hline \multirow[t]{2}{*}{ Italy } & $\mathrm{n}$ & 2426 & 2130 & 7626 & 2041 & 14223 & 9270 & 3461 & 14317 & 4172 & 31220 \\
\hline & $\%$ & 17.1 & 15.0 & 53.6 & 14.4 & & 29.7 & 11.1 & 45.9 & 13.4 & \\
\hline \multirow[t]{2}{*}{ Spain } & $\mathrm{n}$ & 9308 & 1952 & 1206 & 2232 & 14698 & 18651 & 1375 & 1390 & 2385 & 23801 \\
\hline & $\%$ & 63.3 & 13.3 & 8.2 & 15.2 & & 78.4 & 5.8 & 5.8 & 10.0 & \\
\hline \multirow[t]{2}{*}{ United Kingdom } & $\mathrm{n}$ & 3214 & 6514 & 2514 & 7827 & 20069 & 5457 & 14471 & 7152 & 17699 & 44779 \\
\hline & $\%$ & 16 & 32.5 & 12.5 & 39.0 & & 12.2 & 32.3 & 16.0 & 39.5 & \\
\hline \multirow[t]{2}{*}{ The Netherlands } & $\mathrm{n}$ & 1093 & 4136 & 2079 & 2681 & 9989 & 5213 & 9425 & 8797 & 5253 & 28688 \\
\hline & $\%$ & 10.9 & 41.4 & 20.8 & 26.8 & & 18.2 & 32.9 & 30.7 & 18.3 & \\
\hline \multirow[t]{2}{*}{ Greece } & $\mathrm{n}$ & 5393 & 1962 & 1581 & 1718 & 10654 & 9557 & 1007 & 2891 & 1816 & 15271 \\
\hline & $\%$ & 50.6 & 18.4 & 14.8 & 16.1 & & 62.6 & 6.6 & 18.9 & 11.9 & \\
\hline \multirow[t]{2}{*}{ Germany } & $\mathrm{n}$ & 5512 & 6137 & 1156 & 9446 & 22251 & 7017 & 12260 & 2316 & 7833 & 29426 \\
\hline & $\%$ & 24.8 & 27.6 & 5.20 & 42.5 & & 23.9 & 41.7 & 7.9 & 26.6 & \\
\hline \multirow[t]{2}{*}{ Sweden } & $\mathrm{n}$ & 8460 & 4930 & 4790 & 4649 & 22829 & 10064 & 7715 & 4685 & 6982 & 29446 \\
\hline & $\%$ & 37.1 & 21.6 & 20.98 & 20.4 & & 34.2 & 26.2 & 15.9 & 23.7 & \\
\hline \multirow[t]{2}{*}{ Denmark } & $\mathrm{n}$ & 9193 & 7769 & 2054 & 7501 & 26517 & 9128 & 13568 & 3455 & 2996 & 29147 \\
\hline & $\%$ & 34.7 & 29.3 & 7.8 & 28.3 & & 31.3 & 46.6 & 11.9 & 10.3 & \\
\hline \multirow[t]{2}{*}{ Norway } & $\mathrm{n}$ & - & - & - & - & - & 8206 & 12800 & 10306 & 4467 & 35779 \\
\hline & $\%$ & - & & & & & 22.9 & 35.8 & 28.8 & 12.5 & \\
\hline Total & $n$ & 44599 & 35530 & 23006 & 38095 & 141230 & 90507 & 76082 & 90746 & 79302 & 336637 \\
\hline
\end{tabular}

The direction of the overall association between BMI and education was consistent in all countries, although the strength of the association differed between countries. In women the association was weakest in the French cohort and strongest in the Greek cohort (Figure 1). In men, the weakest association was observed in the British centers, while the association was most pronounced in the Italian centers (Figure 2). For all countries, but men of the Greek and Danish cohorts there was a clear trend between level of education and BMI; however, in all countries, BMI was significantly lower for all three higher education categories compared with the lowest education level (data not shown).

The association between WC and education level was stronger for women than for men: compared with the lowest education level, the average waist circumference was statistically significantly lower by $5.20 \mathrm{~cm}$ for female participants in the highest category (Table 4). For men the respective difference was $2.94 \mathrm{~cm}$. Crude associations were similar to the fully adjusted models. Age stratification revealed a stronger difference in WC with education in elderly men compared to younger men. However, for women the difference was larger in the younger than in the older age group. As seen for BMI, the difference between highest and lowest educational group was stronger in never than in current smokers, but again with wide and overlapping confidence intervals. The observed differences were similar between non- or occasional consumers of alcoholic beverages and regular consumers ( $\geq 6 \mathrm{~g}$ ethanol/day). Even among women with a waist circumference $<88 \mathrm{~cm}$, the difference between highest and lowest educated women was statistically significant, but not among men with normal waist $(<102 \mathrm{~cm})$. When adding BMI to the statistical model, all associations for $\mathrm{WC}$ were attenuated and lost statistical significance (data not shown).

These associations were observed in most countries, but the magnitude of the effect differed between countries. In females, the association was weakest in the British centers and strongest in women of the Greek cohort; no statistically significant difference was observed in French women (Figure 3). In almost all centers besides France, women with secondary school or technical/professional school also had significant lower waist circumference compared to women with low education. For men, the relation was smallest in the Danish cohorts and strongest in the Dutch centers (Figure 4). Men of the Greek and the Swedish cohorts had a non-significant difference in waist circumference in participants with secondary school and technical/professional school; for all other centers, the difference was statistically significant (data not shown). 
Table 2 Baseline Characteristics of EPIC participants by sex and highest level of education; 1992-2000

\begin{tabular}{|c|c|c|c|c|c|c|c|c|}
\hline & \multicolumn{4}{|l|}{ Men } & \multicolumn{4}{|l|}{ Women } \\
\hline & $\begin{array}{l}\text { Primary school } \\
\text { or less }\end{array}$ & $\begin{array}{l}\text { Vocational } \\
\text { secondary education }\end{array}$ & $\begin{array}{l}\text { Other secondary } \\
\text { education }\end{array}$ & University & $\begin{array}{l}\text { Primary school } \\
\text { or less }\end{array}$ & $\begin{array}{l}\text { Vocational } \\
\text { secondary education }\end{array}$ & $\begin{array}{l}\text { Other secondary } \\
\text { education }\end{array}$ & University \\
\hline \multirow[t]{2}{*}{ n (\%) } & $44599(31.6)$ & $35530(25.2)$ & $23006(16.3)$ & $38095(27.0)$ & $90507(26.9)$ & $76082(22.6)$ & $90746(27.0)$ & $79302(23.6)$ \\
\hline & \multicolumn{8}{|c|}{ Median (interquartile range) } \\
\hline Age at recruitment (years) & $56.7(50.6-61.8)$ & $52.1(45.5-58.5)$ & $48.7(40.4-56.0)$ & $51.4(43.5-57.7)$ & $54.7(48.7-60.9)$ & $51.1(44.4-56.7)$ & $50.2(44.5-56.1)$ & $48.3(42.9-54.3)$ \\
\hline $\begin{array}{l}\text { Total energy intake (kcal/ } \\
\text { day) }\end{array}$ & $2381(1954-2877)$ & $2341(1938-2806)$ & $2439(2008-2931)$ & $2304(1927-2730)$ & $1823(1498-2209)$ & $1807(1508-2157)$ & $1958(1620-2355)$ & $1935(1608-2311)$ \\
\hline $\begin{array}{l}\text { Alcohol consumption at } \\
\text { baseline }(g / d)\end{array}$ & $12.6(3.0-32.6)$ & $12.8(4.2-29.4)$ & $12.1(3.7-28.1)$ & $15.0(6.1-30.9)$ & $1.5(0.0-7.3)$ & $3.8(1.0-10.6)$ & $4.0(0.7-11.9)$ & $6.2(1.6-13.8)$ \\
\hline BMI $\left(\mathrm{kg} / \mathrm{m}^{2}\right)$ & $27.2(24.9-29.7)$ & $26.1(24.1-28.4)$ & $25.7(23.6-28.0)$ & $25.4(23.4-27.6)$ & $26.3(23.6-29.8)$ & $24.3(22.1-27.2)$ & $23.3(21.3-25.8)$ & $22.7(20.9-25.1)$ \\
\hline \multirow[t]{2}{*}{ WC (cm) } & $97.0(91.0-104.0)$ & $94.0(87.5-100.0)$ & $92.3(86.3-99.0)$ & $92.0(86.0-98.0)$ & $85.0(77.0-93.0)$ & $77.5(71.2-85.3)$ & $77.0(71.0-84.0)$ & $74.0(69.0-80.8)$ \\
\hline & Percent & & & & & & & \\
\hline $\begin{array}{l}\text { Prevalence of overweight } \\
(\%)^{\mathrm{a}}\end{array}$ & 51.8 & 50.0 & 46.5 & 45.1 & 38.2 & 31.2 & 24.4 & 20.1 \\
\hline Prevalence of obesity $(\%)^{a}$ & 22.5 & 14.2 & 12.1 & 9.9 & 23.9 & 11.7 & 7.4 & 5.4 \\
\hline \multicolumn{9}{|l|}{ Smoking status } \\
\hline Never & 27.4 & 30.2 & 34.8 & 40.8 & 60.9 & 46.5 & 56.4 & 56.3 \\
\hline Former & 37.0 & 37.9 & 34.6 & 35.7 & 16.3 & 26.8 & 22.5 & 26.2 \\
\hline Smoker & 34.6 & 31.1 & 29.5 & 22.6 & 21.3 & 25.4 & 18.2 & 15.2 \\
\hline Missing & 1.0 & 0.8 & 1.1 & 0.9 & 1.5 & 1.2 & 3.0 & 2.4 \\
\hline \multicolumn{9}{|l|}{ Physical activity } \\
\hline Inactive & 20.5 & 14.8 & 14.9 & 16.3 & 33.6 & 13.9 & 18.0 & 14.1 \\
\hline Moderately inactive & 23.7 & 25.6 & 28.7 & 35.1 & 27.8 & 27.9 & 32.3 & 34.2 \\
\hline Moderately active & 22.4 & 22.0 & 19.4 & 23.0 & 14.4 & 18.5 & 22.3 & 27.0 \\
\hline Active & 24.8 & 26.8 & 19.7 & 18.4 & 10.7 & 17.9 & 11.3 & 14.5 \\
\hline Missing & 8.6 & 10.8 & 17.2 & 7.3 & 13.6 & 21.8 & 18.2 & 10.2 \\
\hline \multicolumn{9}{|l|}{ Marital status } \\
\hline $\begin{array}{l}\text { Single/divorced/ } \\
\text { separated/widowed }\end{array}$ & 9.4 & 13.2 & 15.9 & 15.8 & 12.8 & 15.8 & 17.0 & 24.9 \\
\hline $\begin{array}{l}\text { Married/living } \\
\text { together }\end{array}$ & 48.3 & 58.4 & 65.8 & 58.3 & 54.5 & 61.5 & 74.8 & 66.5 \\
\hline Missing & 42.3 & 28.4 & 18.3 & 25.9 & 32.7 & 22.7 & 8.2 & 8.6 \\
\hline
\end{tabular}

overweight defined as $\mathrm{BMI} \geq 25$ and $<30$, obesity defined as $\mathrm{BMI} \geq 30$.

${ }^{b}$ does not add up to $100 \%$ due to missing information. 
Table 3 Association ${ }^{a, b}$ between level of education and BMI $\left(\mathrm{kg} / \mathrm{m}^{2}\right)$ in EPIC by sex and subgroups; EPIC participants interviewed between 1992 and 2000

\begin{tabular}{|c|c|c|c|c|c|c|c|}
\hline & \multirow[t]{2}{*}{ Primary school or less } & \multicolumn{2}{|c|}{ Vocational secondary training } & \multicolumn{2}{|c|}{ Other secondary education } & \multicolumn{2}{|c|}{ University } \\
\hline & & Estimate & $95 \% \mathrm{Cl}$ & Estimate & $95 \% \mathrm{Ci}$ & Estimate & $95 \% \mathrm{Cl}$ \\
\hline \multicolumn{8}{|l|}{ BMI $\left(\mathrm{kg} / \mathrm{m}^{2}\right)$} \\
\hline \multicolumn{8}{|l|}{ Women } \\
\hline Overall crude & ref. & -1.16 & -2.46 to 0.14 & -1.58 & -2.69 to -0.47 & -2.25 & -3.39 to -1.10 \\
\hline Overall adjusted ${ }^{a}$ & ref. & -0.98 & -1.11 to -0.85 & -1.44 & -1.69 to -1.20 & -2.12 & -2.49 to -1.76 \\
\hline Age $>=60$ & ref. & -0.84 & -0.98 to -0.70 & -1.25 & -1.47 to -1.03 & -1.56 & -1.88 to -1.24 \\
\hline Age $<60$ & ref. & -1.30 & -1.56 to -1.04 & -1.46 & -1.72 to -1.20 & -2.13 & -2.48 to -1.78 \\
\hline Never smoker & ref. & -1.19 & -3.45 to 1.08 & -1.68 & -3.70 to 0.35 & -2.37 & -4.42 to -0.32 \\
\hline Former smoker & ref. & -1.03 & -2.16 to 0.10 & -1.51 & -2.56 to -0.45 & -2.04 & -3.08 to -0.99 \\
\hline Current smoker & ref. & -0.90 & -1.52 to -0.29 & -1.05 & -1.65 to -0.45 & -1.59 & -2.23 to -0.95 \\
\hline Alcohol intake $0-<6 \mathrm{~g} /$ day & ref. & -1.10 & -2.40 to 0.20 & -1.54 & -2.67 to -0.41 & -2.23 & -3.38 to -1.08 \\
\hline Alcohol intake $\geq 6 \mathrm{~g} /$ day & ref. & -1.05 & -2.14 to 0.04 & -1.42 & -2.35 to -0.50 & -1.97 & -2.91 to -1.03 \\
\hline $\mathrm{BMI}<25 \mathrm{~kg} / \mathrm{m}^{2}$ & ref. & -0.15 & -0.65 to 0.35 & -0.27 & -0.72 to 0.19 & -0.47 & -0.92 to -0.02 \\
\hline $\mathrm{BMI} \geq 25 \mathrm{~kg} / \mathrm{m}^{2}$ & ref. & -0.57 & -1.16 to 0.01 & -0.76 & -1.25 to -0.27 & -1.08 & -1.64 to -0.53 \\
\hline \multicolumn{8}{|l|}{ Men } \\
\hline Overall crude & ref. & -0.56 & -1.68 to 0.56 & -0.81 & -1.91 to 0.29 & -1.28 & -2.45 to -0.10 \\
\hline Overall adj. & ref. & -0.52 & -0.61 to -0.44 & -0.84 & -1.00 to -0.69 & -1.28 & -1.50 to -1.07 \\
\hline Age $>=60$ & ref. & -0.61 & -0.79 to -0.44 & -0.70 & -0.90 to -0.49 & -0.97 & -1.16 to -0.77 \\
\hline Age $<60$ & ref. & -0.55 & -0.68 to -0.43 & -0.84 & -1.01 to -0.67 & -1.36 & -1.55 to -1.18 \\
\hline Never smoker & ref. & -0.66 & -1.27 to -0.06 & -0.95 & -1.59 to -0.31 & -1.52 & -2.23 to -0.82 \\
\hline Former smoker & ref. & -0.63 & -0.99 to -0.27 & -0.83 & -1.24 to -0.42 & -1.28 & -1.80 to -0.75 \\
\hline Current smoker & ref. & -0.50 & -1.67 to 0.67 & -0.85 & -2.03 to 0.33 & -1.14 & -2.34 to 0.05 \\
\hline Alcohol intake $0-<6 \mathrm{~g} /$ day & ref. & -0.67 & -1.83 to 0.49 & -0.89 & -2.06 to 0.28 & -1.42 & -2.68 to -0.15 \\
\hline Alcohol intake $\geq 6 \mathrm{~g} /$ day & ref. & -0.56 & -1.16 to 0.04 & -0.87 & -1.46 to -0.28 & -1.33 & -2.02 to -0.64 \\
\hline $\mathrm{BMI}<25 \mathrm{~kg} / \mathrm{m}^{2}$ & ref. & -0.01 & -0.16 to 0.15 & -0.02 & -0.20 to 0.15 & -0.04 & -0.24 to 0.15 \\
\hline $\mathrm{BMI} \geq 25 \mathrm{~kg} / \mathrm{m}^{2}$ & ref. & -0.52 & -0.79 to -0.24 & -0.62 & -0.88 to -0.37 & -0.95 & -1.25 to -0.66 \\
\hline
\end{tabular}

adjusted for recruitment age, smoking, physical activity, alcohol consumption, total energy intake (when applicable).

${ }^{b}$ the association between education and BMI or WC across all countries was estimated using multilevel mixed linear models with random intercepts and coefficients both at the centre and country level.

\section{Discussion}

WC is a measure of central adiposity, while BMI is generally considered as an indicator of overall obesity. In this European cohort, we observed that higher educated participants had lower BMI and as well as smaller WC. However, when adjusting WC for BMI, the association of education with WC was strongly attenuated, indicating that BMI is a good indicator of the association between education and obesity.

This inverse association between BMI and educational level is in line with results in other studies [2,3,13-15], some also showing a stronger association for women than for men $[3,5,16,17]$. However, the reason for this difference is still mostly unclear. Differences between SES categories in physical activity and energy intake might explain part of the association between SES and BMI [18], but this is not observed in our and other studies [19]. Furthermore, it could not be shown that SES status affects either total energy intake or macronutrients composition of the diet [20]. Similarly, in EPIC total energy intake did not differ strongly between the education categories (see Table 2). Another explanation is that underreporting might be more common in less educated subjects. Individuals with a higher BMI as well as those who want to reduce weight tend to underreport dietary intake to a greater degree than individuals with lower BMI [21-23]. This behaviour seems to be more common among women than among men in EPIC [24]. Since $74 \%$ of the subjects in the lowest education category are either overweight or obese, the impact of dietary underreporting may be more meaningful among less educated people. The observed inverse SES gradients in BMI and WC are, thus, likely underestimated. Furthermore, it can be speculated that foods with a high energy density and an unhealthy image are underreported. Energy expenditure is a further important factor that influences BMI. Subjects in the lowest education level stated to be inactive most frequently $(22.4 \%$ of men and $38.9 \%$ of females). It has also been shown that individuals who overestimated energy expenditure on the 

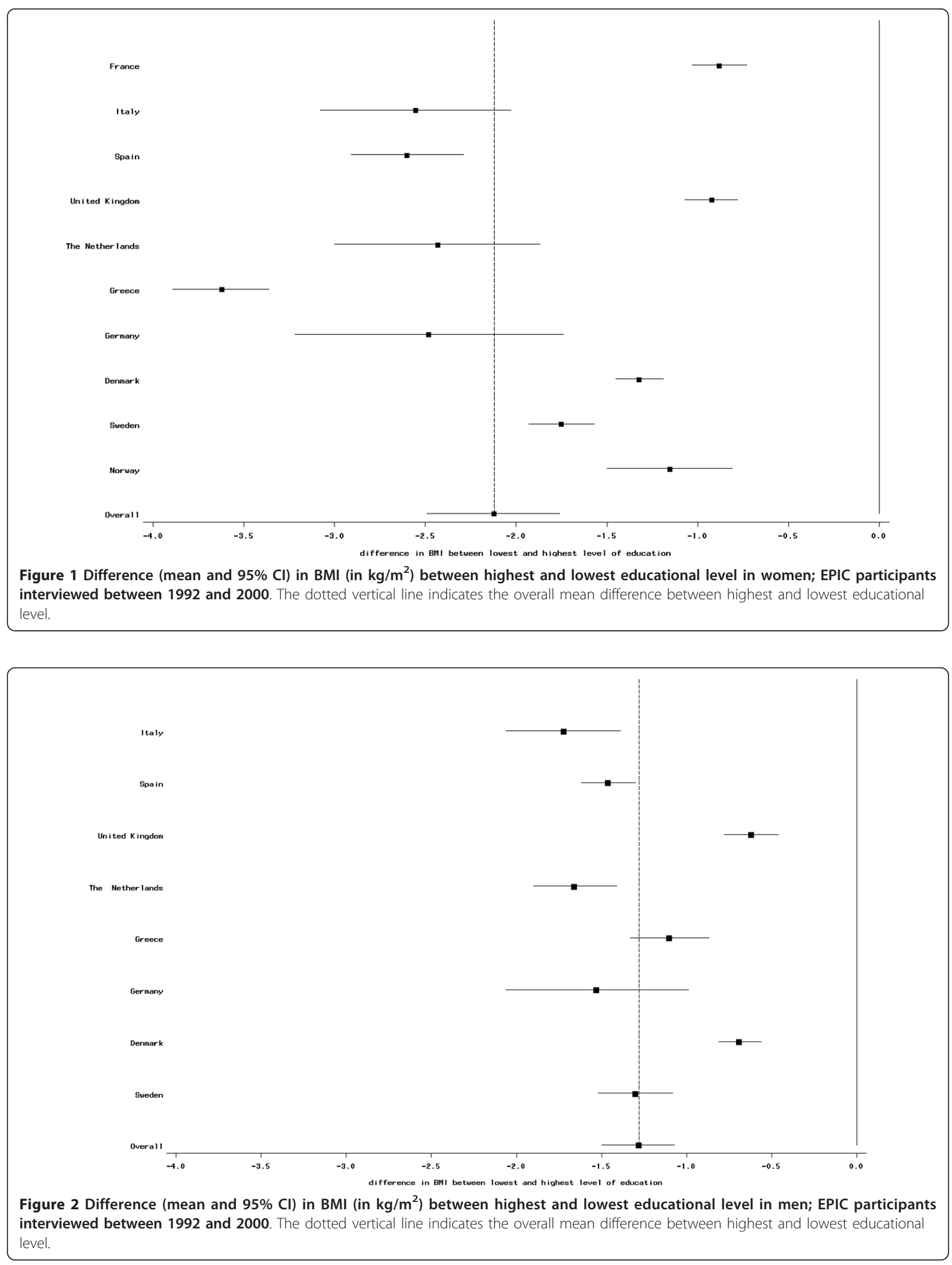
Table 4 Association ${ }^{a, b}$ between level of education and waist circumference $(\mathrm{cm})$ in EPIC by sex and subgroups; EPIC participants interviewed between 1992 and 2000

\begin{tabular}{|c|c|c|c|c|c|c|c|}
\hline & \multirow[t]{2}{*}{ Primary school or less } & \multicolumn{2}{|c|}{$\begin{array}{c}\text { Vocational secondary } \\
\text { education }\end{array}$} & \multicolumn{2}{|c|}{$\begin{array}{l}\text { Other secondary } \\
\text { education }\end{array}$} & \multicolumn{2}{|c|}{ University } \\
\hline & & Estimate & $95 \% \mathrm{Cl}$ & Estimate & $95 \% \mathrm{Ci}$ & Estimate & $95 \% \mathrm{Cl}$ \\
\hline \multicolumn{8}{|l|}{ Waist (cm) } \\
\hline \multicolumn{8}{|l|}{ Women } \\
\hline Overall crude & ref. & -3.23 & -5.72 to -0.74 & -3.98 & -6.10 to -1.87 & -5.43 & -7.76 to -3.10 \\
\hline Overall adj. & ref. & -2.62 & -2.94 to -2.30 & -3.71 & -4.32 to -3.10 & -5.20 & -6.10 to -4.30 \\
\hline Age $>=60$ & ref. & -2.06 & -2.54 to -1.58 & -3.02 & -3.49 to -2.56 & -3.83 & -4.74 to -2.91 \\
\hline Age $<60$ & ref. & -3.39 & -3.99 to -2.80 & -4.09 & -4.57 to -3.62 & -5.47 & -6.19 to -4.76 \\
\hline Never smoker & ref. & -3.66 & -5.84 to -1.48 & -4.44 & -6.38 to -2.50 & -5.85 & -7.98 to -3.72 \\
\hline Former smoker & ref. & -2.94 & -4.96 to -0.91 & -3.73 & -5.77 to -1.70 & -5.06 & -7.05 to -3.07 \\
\hline Current smoker & ref. & -2.69 & -3.85 to -1.54 & -2.88 & -4.04 to -1.72 & -4.11 & -5.29 to -2.92 \\
\hline Alcohol intake $0-<6 \mathrm{~g} /$ day & ref. & -3.21 & -5.59 to -0.83 & -3.95 & -6.02 to -1.89 & -5.41 & -7.73 to -3.09 \\
\hline Alcohol intake $\geq 6 \mathrm{~g} /$ day & ref. & -3.37 & -5.07 to -1.68 & -4.02 & -5.68 to -2.37 & -5.19 & -6.84 to -3.54 \\
\hline waist circumf. $<88 \mathrm{~cm}$ & ref. & -1.28 & -2.57 to 0.01 & -1.65 & -2.91 to -0.40 & -2.25 & -3.51 to -0.98 \\
\hline waist circumf. $\geq 88 \mathrm{~cm}$ & ref. & -0.85 & -1.47 to -0.23 & -1.31 & -1.70 to -0.91 & -1.63 & -2.32 to -0.94 \\
\hline \multicolumn{8}{|l|}{ Men } \\
\hline Overall crude & ref. & -1.49 & -3.28 to 0.30 & -1.75 & -3.58 to 0.07 & -2.84 & -4.90 to -0.78 \\
\hline Overall adj. & ref. & -1.25 & -1.50 to -1.01 & -1.97 & -2.41 to -1.54 & -2.94 & -3.55 to -2.33 \\
\hline Age $>=60$ & ref. & -1.44 & -1.95 to -0.93 & -1.53 & -2.07 to -.99 & -2.15 & -2.70 to -1.61 \\
\hline Age $<60$ & ref. & -1.39 & -1.71 to -1.08 & -1.96 & -2.39 to -1.53 & -1.96 & -3.63 to -2.67 \\
\hline Never smoker & ref. & -1.93 & -3.64 to -0.22 & -2.29 & -4.03 to -0.55 & -3.70 & -5.60 to -1.80 \\
\hline Former smoker & ref. & -1.51 & -3.17 to 0.14 & -1.92 & -3.71 to -0.14 & -3.06 & -4.99 to -1.12 \\
\hline Current smoker & ref. & -1.33 & -4.66 to 2.01 & -2.08 & -5.48 to 1.32 & -2.51 & -5.88 to 0.86 \\
\hline Alcohol intake $0-<6 \mathrm{~g} /$ day & ref. & -1.67 & -4.95 to 1.61 & -2.05 & -5.50 to 1.40 & -3.26 & -6.78 to 0.26 \\
\hline Alcohol intake $\geq 6 \mathrm{~g} /$ day & ref. & -1.53 & -3.26 to 0.21 & -2.15 & -3.88 to -0.42 & -3.14 & -5.07 to -1.22 \\
\hline Waist circumf. < $102 \mathrm{~cm}$ & ref. & -0.40 & -1.61 to 0.82 & -0.76 & -2.10 to 0.57 & -1.29 & -2.67 to 0.09 \\
\hline Waist circumf. $\geq 102 \mathrm{~cm}$ & ref. & -0.60 & -0.98 to -0.22 & -0.54 & -0.99 to -0.10 & -1.03 & -1.40 to -0.66 \\
\hline
\end{tabular}

adjusted for recruitment age, smoking, physical activity, alcohol consumption, total energy intake (when applicable).

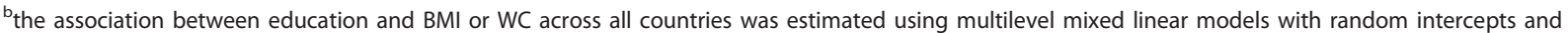
coefficients both at the centre and country level.

physical activity records had a significantly higher BMI and percentage of body fat compared with those that accurately estimated their energy expenditure $[25,26]$.

Overall, we observed a difference in BMI of $2.12 \mathrm{~kg} / \mathrm{m}^{2}$ in women and of $1.28 \mathrm{~kg} / \mathrm{m}^{2}$ in men when comparing highest with lowest educational level. Although Molarius et al. $[5,27]$ did not estimate an overall difference in the MONICA surveys, our results are comparable with the MONICA results in range. It is interesting to note that the association between education and BMI was smallest in women from the Scandinavian centers as well as the UK cohort and the French. However, for France this could be explained by the relative homogenous SES level at study intake, because only teachers and other school employees were recruited. So, although at younger age the educational level might have differed, later on inequalities in SES disappeared. The association was strongest in Greece, but associations in the Spanish and
Italian cohorts were more comparable to associations in centers from Middle Europe. Recently, Roskam et al. [27] showed that educational inequalities in overweight and obesity were largest in Mediterranean women, whereas they were largest in French, German, Belgian, and Czech women in the MONICA surveys [5]. For men, the inequalities are in general smaller and no clear geographical pattern emerge for Southern, Central, and Northern Europe [5,27]. In our analysis, it has to be taken into account, that although most cohorts were recruited from the general population, the cohorts are in the majority not representative of a country. Furthermore, as some cohorts have been recruited from specific subgroups of the population such as blood donors comparisons between the cohorts should be interpreted with caution.

Our study includes a large sample size and participants from ten European countries. However, for some centers, i.e., France, Oxford, and Norway, only self- 


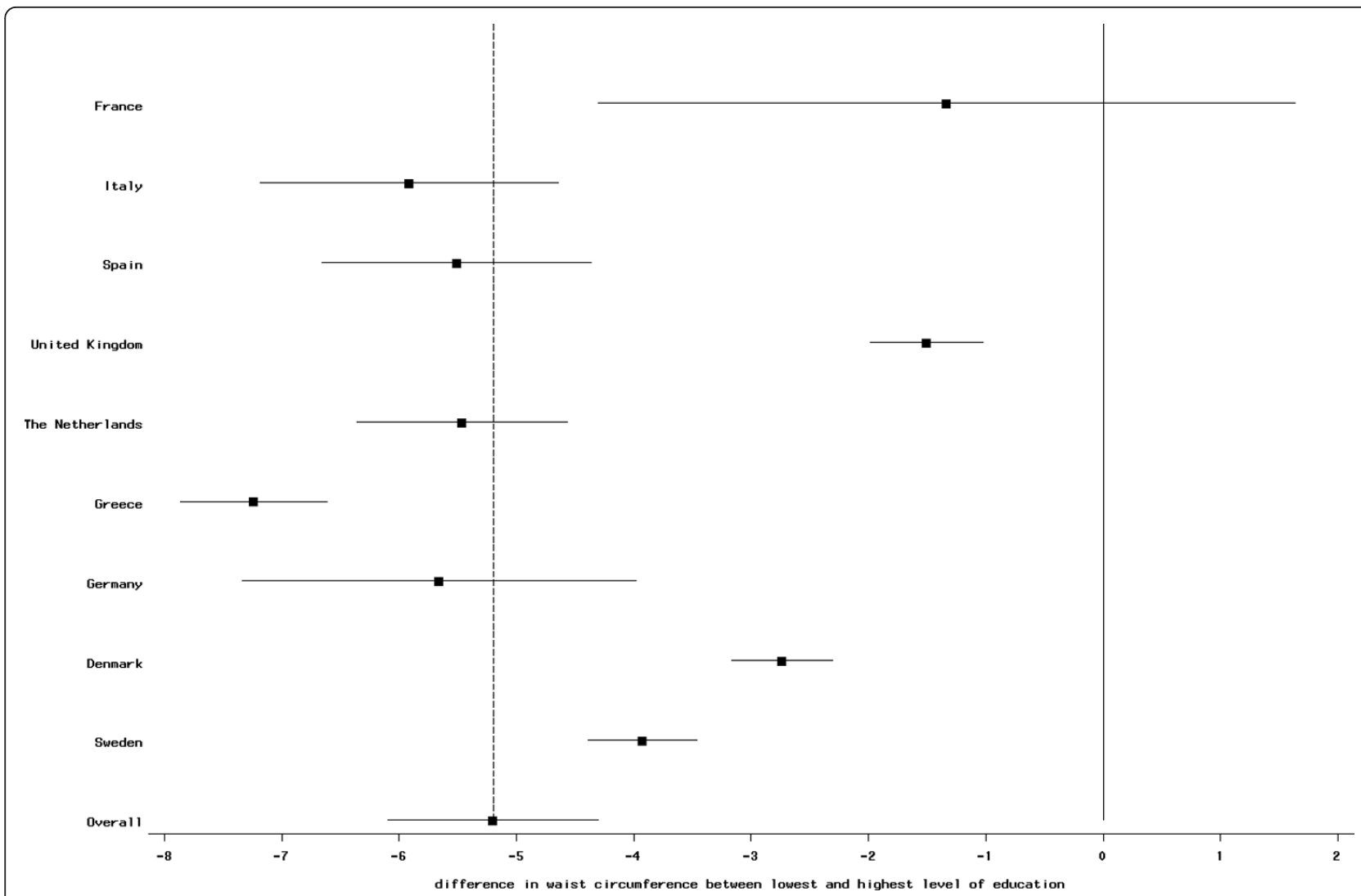

Figure 3 Difference (mean and $95 \% \mathrm{Cl}$ ) in waist circumference (in $\mathrm{cm}$ ) between highest and lowest educational level in women; EPIC participants interviewed between 1992 and 2000. The dotted vertical line indicates the overall mean difference between highest and lowest educational level.

reported information was available. Assuming an underreporting of weight and $\mathrm{WC}$ in these centers that is stronger in less than better educated individuals, this would cause a weaker association between BMI and WC and SES compared with other centers. This is what we indeed observed (Figures 1, 2, 3 and 4), although we still observed statistically significant relations between BMI and education in these centers. Differences in measurement of waist circumference between centers might also partly explain differences in the association between waist circumference and education between the centers. The EPIC participants were recruited over a time period of eight years (from 1992 to 2000). Changes in the prevalence of obesity and changes in the structure of the educational system (i.e., a trend towards a higher education in the general population) might lead to a small cohort effect, such that the association between SES and BMI could be different between subjects that have been recruited at the beginning of this period and subjects that have been recruited towards the end. Our data was too limited to study this.

Education was used in our analysis as an indicator of SES. Low educational levels may influence obesity- related behaviour such as diet and physical activity, which may be caused by lack of knowledge [28]. Compared to occupation and income, education is stable throughout life and reflects childhood conditions. However, stability can be a limitation because it does not take social advancements and status later in life into account [29]. In addition, SES of the spouse may be important, too. Neglecting this may result in an error that is probably more severe in older women, who adapted the SES of their partners after marriage. This may also explain the stronger effect seen in younger subjects (< 60 years of age). However, adjusting for marital status did not change our study results. Further variables to better capture a subject's SES such as household income have not consistently been assessed in all EPIC centers. The fact that the educational systems are diverse in the various European countries may lead to further misclassification. However, the lowest (primary school or less) as well as the highest educational level (university degree) should be rather comparable for all countries. Also, efforts have been made to correct for misclassification by comparing highest school level with years of schooling. 


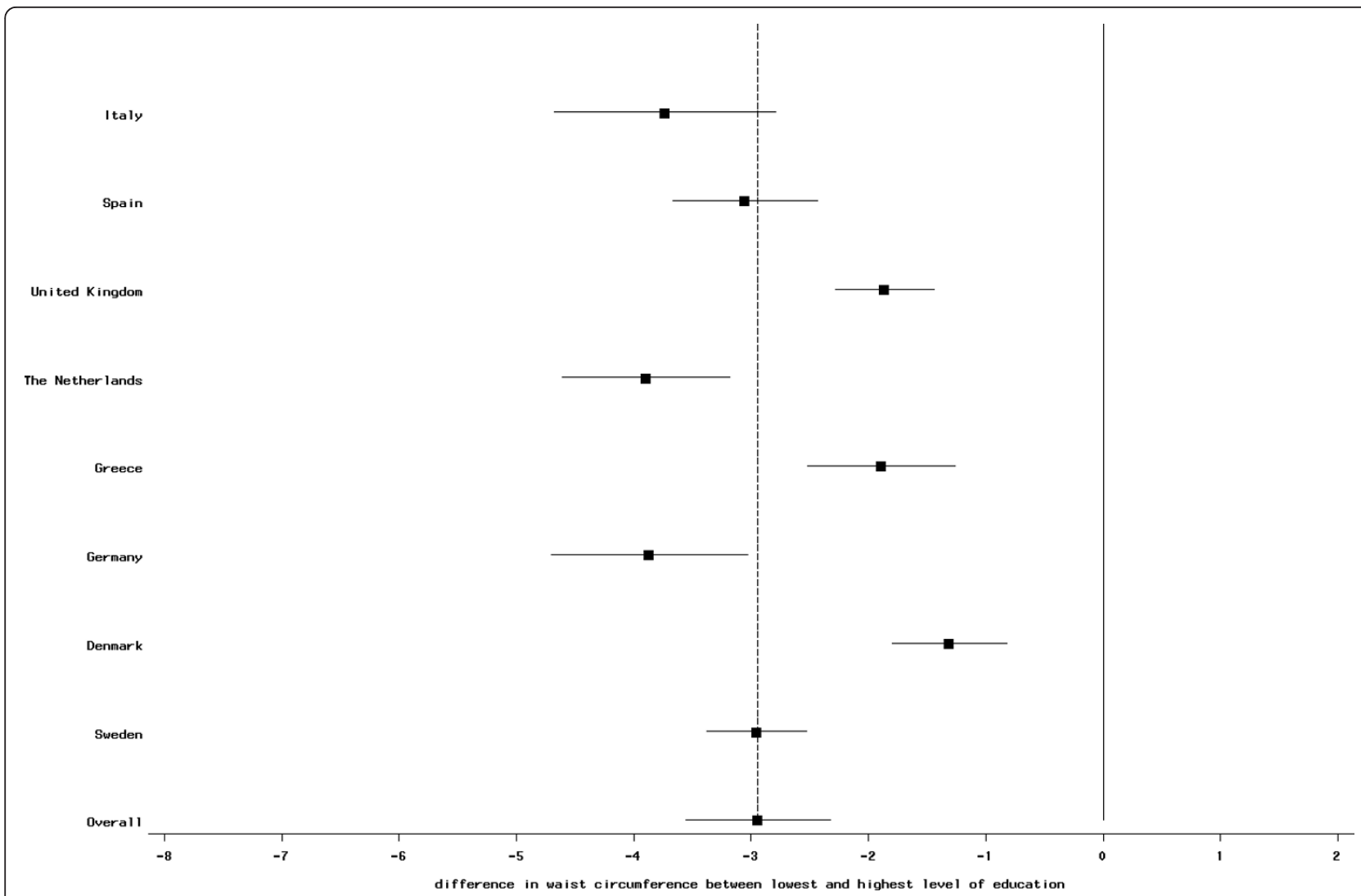

Figure 4 Difference (mean and $95 \% \mathrm{Cl}$ ) in waist circumference (in $\mathrm{cm}$ ) between highest and lowest educational level in men; EPIC participants interviewed between 1992 and 2000. The dotted vertical line indicates the overall mean difference between highest and lowest educational level.

\section{Conclusion}

In all European EPIC cohorts, there was an inverse association seen between BMI as well as WC and education level. Our results confirm previous literature on SES and BMI; as well add new information for the association between WC and level of education.

Public Health Programs that aim to reduce overweight and obesity should primarily focus on the lower educated population, such that these programs are better targeted to the addressed population group.

\section{Acknowledgements}

The work described in this paper was carried out with support of the European Commission: Grant no DG Sanco, project number: 2005328 The work was further financially supported by the European Commission: Public Health and Consumer Protection Directorate 1993-2004; Research Directorate-General 2005-."; Ligue contre le Cancer, Societé 3M, Mutuelle Générale de l'Education Nationale, Institut National de la Santé et de la Recherche Médicale (INSERM) (France); German Cancer Aid, German Cancer Research Center, Federal Ministry of Education and Research (Germany); Danish Cancer Society (Denmark); Health Research Fund (FIS) of the Spanish Ministry of Health, The participating regional governments and institutions (Spain); Cancer Research UK, Medical Research Council, Stroke Association, British Heart Foundation, Department of Health, Food Standards Agency, the Wellcome Trust (United Kingdom); Greek Ministry of Health and Social Solidarity, Hellenic Health Foundation and Stavros Niarchos Foundation
(Greece); Italian Association for Research on Cancer, National Research Council (Italy); Dutch Ministry of Public Health, Welfare and Sports, Dutch Ministry of Health, Dutch Prevention Funds, LK Research Funds, Dutch ZON (Zorg Onderzoek Nederland), World Cancer Research Fund (WCRF) (the Netherlands); Swedish Cancer Society, Swedish Scientific Council, Regional Government of Skane (Sweden); Norwegian Cancer Society (Norway).

\section{Author details}

${ }^{1}$ Division of Cancer Epidemiology, German Cancer Research Centre, Heidelberg, Germany. 'Institute of Epidemiology, Helmholtz Centre Munich, Neuherberg, Germany. ${ }^{3}$ Julius Centre for Health Sciences and Primary Care, University Medical Centre Utrecht, Utrecht, The Netherlands. ${ }^{4}$ National Institute for Public Health and the Environment (RIVM), Bilthoven, The Netherlands. ${ }^{5}$ Academic Medical Centre (AMC), University of Amsterdam, Amsterdam, The Netherlands. ${ }^{6}$ Medical Research Council, Epidemiology Unit, Institute of Metabolic Science, Cambridge, UK. ${ }^{7}$ Department of Epidemiology \& Public Health, Imperial College London, London, UK. ${ }^{8}$ Unit of Nutrition, Environment and Cancer, Catalan Institute of Oncology, IDIBELL, Barcelona, Spain. ${ }^{9}$ Epidemiology Service, Murcia Health Council, Murcia, Spain. ${ }^{10}$ Preventive Medicine and Public Health Unit, Murcia Medical School, Murcia, Spain. ${ }^{11} \mathrm{CIBER}$ Epidemiología y Salud Pública (CIBERESP), Spain. ${ }^{12}$ Andalusian School of Public Health, Granada, Spain. ${ }^{13}$ Public Health Department of Gipuzkoa, San Sebastian, Spain. ${ }^{14}$ Public Health Institute of Navarra, Pamplona, Spain. ${ }^{15}$ Public Health and Participation Directorate, Health and Health Care Services Council, Asturias, Spain. ${ }^{16}$ Cancer Epidemiology Unit, University of Oxford, Oxford, UK. ${ }^{17}$ Department of Public Health and Primary Care, University of Cambridge, Cambridge, UK.

${ }^{18}$ Department of Cardiology, Aalborg Hospital, Aarhus University Hospital, Aalborg, Denmark. ${ }^{19}$ Department of Clinical Epidemiology, Aarhus University Hospital, Aalborg, Denmark. ${ }^{20}$ Danish Cancer Society, Institute of Cancer 
Epidemiology, Copenhagen, Denmark. ${ }^{21}$ Nutritional Epidemiology Unit, Fondazione IRCCS Istituto Nazionale dei Tumori, Milan, Italy. ${ }^{22}$ Department of Clinical and Experimental Medicine - Federico II University, Naples, Italy. ${ }^{23}$ Cancer Registry and Histopathology Unit, Department of Oncology, "Civile M.P.Arezzo" Hospital, Ragusa, Italy. ${ }^{24}$ Molecular and Nutritional Epidemiology Unit, Cancer Research and Prevention Institute (ISPO), Florence, Italy. ${ }^{25}$ ISI Foundation, Torino, Italy. ${ }^{26}$ Environmental Epidemiology, Imperial College London, London, UK. ${ }^{27}$ Department of Hygiene and Epidemiology, University of Athens Medical School, Athens, Greece. ${ }^{28}$ Hellenic Health Foundation, Greece. ${ }^{29} \mathrm{German}$ Institute of Human Nutrition PotsdamRehbrücke, Nuthetal, Germany. ${ }^{30}$ Department of Medical Biosciences, Pathology, Umeå University, Umeå, Sweden. ${ }^{31}$ Department of Odontology, Umeå University, Umeå, Sweden. ${ }^{32}$ Department of Oncology, Lund University Hospital, Lund, Sweden. ${ }^{33}$ Department of Surgery, Malmö University Hospital, Malmö, Sweden. ${ }^{34}$ Institute of Community Medicine, University of Tromsø, Tromsø, Norway. ${ }^{35}$ Inserm ERI20 and Paris South University, Institut Gustave-Roussy, Villejuif, France. ${ }^{36}$ International Agency for Research on Cancer, Lyon, France. ${ }^{37}$ Insitute of Social and Preventive Medicine, University of Zurich, Zurich, Switzerland.

\section{Authors' contributions}

PHMP: principal investigator of the EPIC-PANACEA project and guarantor of the article; ER: overall coordinator of the EPIC study, which was conceptualized, designed, and implemented in collaboration with the main investigators in the collaborating countries as follows: Denmark ( $K O$ and $A$ Tj), France (FC-C), Germany (RK), Greece (ATr), Italy (RT, and PV), Netherlands (HBB-d-M and PHMP), Spain (LR, M-JT, MD, and AB), Sweden (JM), and United Kingdom (NW and K-TK) (these authors contributed to the study design, subject recruitment, and data collection and acquisition and are responsible for the ongoing follow-up and management of the EPIC cohort); SH, SRo and JL: conceived the current study; SH and SRo: responsible for the design of the study, analyses of data, interpretation of results; SH drafting of the manuscript, taking into account the comments and suggestions of the coauthors; contributors from the collaborating centers (AMM, AK, HB, DR, NT, EM, LR, FLC, PGAvB, MUJ, JH, CA, AM, GM, PO, AN, MMB, AS, BVG, IJ, SB, TB, $G F, T M, T N$, SRi and NS): provided the original data, information on the respective populations, and advice on study design, analysis, and interpretation of the results; and all coauthors: had the opportunity to comment on the analysis and interpretation of the findings and approved the final version of the manuscript.

\section{Competing interests}

The authors declare that they have no competing interests.

Received: 6 September 2010 Accepted: 17 March 2011 Published: 17 March 2011

\section{References}

1. James PT: Obesity: The worldwide epidemic. Clin Dermatol 2004, 22(4):276-280.

2. Wyatt SB, Winters KP, Dubbert PM: Overweight and obesity: prevalence, consequences, and causes of a growing public health problem. Am J Med Sci 2006, 331(4):166-174

3. McLaren L: Socioeconomic Status and Obesity. Epidemiol Rev 2007, 29(1):29-48.

4. Zhang $Q$, Wang $Y$ : Trends in the Association between Obesity and Socioeconomic Status in U.S. Adults: 1971 to 2000. Obesity Res 2004, 12(10):1622-1632.

5. Molarius A, Seidell JC, Sans S, Tuomilehto J, Kuulasmaa K: Educational level, relative body weight, and changes in their association over 10 years: an international perspective from the WHO MONICA Project. Am J Public Health 2000, 90(8):1260-1268.

6. Pischon T, Boeing H, Hoffmann K, Bergmann M, Schulze MB, Overvad K, van der Schouw YT, Spencer E, Moons KGM, Tjonneland A, et al: General and Abdominal Adiposity and Risk of Death in Europe. N Engl J Med 2008, 359(20):2105-2120

7. Riboli E, Hunt K, Slimani N, Ferrari P, Norat T, Fahey M, Charrondiere UR, Hemon B, Casagrande C, Vignat J, et al: European Prospective Investigation into Cancer and Nutrition (EPIC): study populations and data collection. Public Health Nutr 2002, 5(6B):1113-1124.
8. Haftenberger M, Lahmann PH, Panico S, Gonzalez CA, Seidell JC, Boeing H, Giurdanella MC, Krogh V, Bueno-de-Mesquita HB, Peeters PH, et al: Overweight, obesity and fat distribution in 50- to 64-year-old participants in the European Prospective Investigation into Cancer and Nutrition (EPIC). Public Health Nutr 2002, 5(6B):1147-1162.

9. Spencer EA, Appleby PN, Davey GK, Key TJ: Validity of self-reported height and weight in 4808 EPIC-Oxford participants. Public Health Nutr 2002, 5(4):561-565.

10. Spencer EA, Roddam AW, Key TJ: Accuracy of self-reported waist and hip measurements in 4492 EPIC-Oxford participants. Public Health Nutr 2004, 7(6):723-727.

11. Wareham NJ, Jakes RW, Rennie KL, Schuit J, Mitchell J, Hennings S, Day NE: Validity and repeatability of a simple index derived from the short physical activity questionnaire used in the European Prospective Investigation into Cancer and Nutrition (EPIC) study. Public Health Nutr 2003, 6(4):407-413.

12. WHO: Obesity: preventing and managing the global epidemic. Report on a WHO consultation. 2000.

13. Borodulin $K$, Mäkinen $T$, Fogelholm M, Lahti-Koski M, Prättälä R: Trends and socioeconomic differences in overweight among physically active and inactive Finns in 1978-2002. Prev Med 2007, 45(2-3):157-162.

14. Hajian-Tilaki $\mathrm{KO}$, Heidari B: Prevalence of obesity, central obesity and the associated factors in urban population aged 20-70 years, in the north of Iran: a population-based study and regression approach. Obes Rev 2007, 8(1):3-10.

15. Aranceta J, Pérez-Rodrigo C, Serra-Majem L, Bellido D, de la Torre ML, Formiguera $\mathrm{X}$, Moreno B: Prevention of overweight and obesity: a Spanish approach. Public Health Nutr 2007, 10(10A):1187-1193.

16. Sabanayagam C, Shankar A, Wong TY, Saw SM, Foster PJ: Socioeconomic status and overweight/obesity in an adult Chinese population in Singapore. J Epidemiol 2007, 17(5):161-168.

17. Sánchez-Vaznaugh EV, Kawachi I, Subramanian SV, Sánchez BN, AcevedoGarcia D: Do socioeconomic gradients in body mass index vary by race/ ethnicity, gender, and birthplace? Am J Epidemiol 2009, 169(9):1102-1112

18. Manios Y, Panagiotakos DB, Pitsavos C, Polychronopoulos E, Stefanadis C: Implication of socio-economic status on the prevalence of overweight and obesity in Greek adults: the ATTICA study. Health Policy 2005, 74(2):224-232.

19. Drewnowski A, Specter SE: Poverty and obesity: the role of energy density and energy costs. Am J Clin Nutr 2004, 79(1):6-16.

20. Darmon N, Drewnowski A: Does social class predict diet quality? Am J Clin Nutr 2008, 87(5):1107-1117.

21. Johansson G, Wikman A, Ahren AM, Hallmans G, Johansson I: Underreporting of energy intake in repeated 24-hour recalls related to gender, age, weight status, day of interview, educational level, reported food intake, smoking habits and area of living. Public Health Nutr 2001, 4(4):919-927.

22. Johansson L, Solvoll K, Bjørneboe GE, Drevon CA: Under- and overreporting of energy intake related to weight status and lifestyle in a nationwide sample. Am J Clin Nutr 1998, 68(2):266-274.

23. Braam LA, Ocke MC, Bueno-de-Mesquita HB, Seidell JC: Determinants of obesity-related underreporting of energy intake. Am J Epidemiol 1998, 147(11):1081-1086.

24. Ferrari P, Slimani N, Ciampi A, Trichopoulou A, Naska A, Lauria C, Veglia F, Bueno-de-Mesquita HB, Ocke MC, Brustad M, et al: Evaluation of underand overreporting of energy intake in the 24-hour diet recalls in the European Prospective Investigation into Cancer and Nutrition (EPIC). Public Health Nutr 2002, 5(6B):1329-1345.

25. Buchowski MS, Townsend KM, Chen KY, Acra SA, Sun M: Energy expenditure determined by self-reported physical activity is related to body fatness. Obes Res 1999, 7(1):23-33.

26. Irwin ML, Ainsworth BE, Conway JM: Estimation of energy expenditure from physical activity measures: determinants of accuracy. Obes Res 2001, 9(9):517-525.

27. Roskam A-JR, Kunst AE, Van Oyen H, Demarest S, Klumbiene J, Regidor E, Helmert U, Jusot F, Dzurova D, Mackenbach JP, et al: Comparative appraisal of educational inequalities in overweight and obesity among adults in 19 European countries. Int J Epidemiol 2009, dyp329.

28. Ball $K$, Crawford D: Socioeconomic status and weight change in adults: a review. Soc Sci Med 2005, 60:1987-2010. 
29. Regidor E: Measures of health inequalities: part 2. J Epidemiol Community Health 2004, 58(11):900-903.

\section{Pre-publication history}

The pre-publication history for this paper can be accessed here:

http://www.biomedcentral.com/1471-2458/11/169/prepub

doi:10.1186/1471-2458-11-169

Cite this article as: Hermann et al.: The association of education with body mass index and waist circumference in the EPIC-PANACEA study. BMC Public Health 2011 11:169.

Submit your next manuscript to BioMed Central and take full advantage of:

- Convenient online submission

- Thorough peer review

- No space constraints or color figure charges

- Immediate publication on acceptance

- Inclusion in PubMed, CAS, Scopus and Google Scholar

- Research which is freely available for redistribution

Submit your manuscript at www.biomedcentral.com/submit
Ciomed Central 